\title{
Noradrenergic Deficits in Parkinson Disease Imaged with ${ }^{11}$ C-MeNER
}

\author{
Adjmal Nahimi ${ }^{1-3}$, Michael Sommerauer ${ }^{1}$, Martin B. Kinnerup ${ }^{1}$, Karen $\varnothing_{\text {stergaard }}^{3}$, Michael Wintherdahl ${ }^{1}$, \\ Jan Jacobsen $^{1}$, Anna Schacht ${ }^{1}$, Birger Johnsen ${ }^{2}$, Malene F. Damholdt ${ }^{4,5}$, Per Borghammer ${ }^{1}$, and Albert Gjedde ${ }^{6-9}$ \\ ${ }^{I}$ Department of Nuclear Medicine and PET Centre, Aarhus University Hospital, Aarhus, Denmark; ${ }^{2}$ Department of Neurophysiology, \\ Aarhus University Hospital, Aarhus, Denmark; ${ }^{3}$ Department of Neurology, Aarhus University Hospital, Aarhus, Denmark; ${ }^{4}$ Unit for \\ Psychooncology and Health Psychology, Aarhus University, Aarhus, Denmark; ${ }^{5}$ Department of Clinical Medicine, Aarhus University, \\ Aarhus, Denmark; ${ }^{6}$ Department of Neuroscience and Pharmacology, University of Copenhagen, Copenhagen, Denmark; ${ }^{7}$ Department of \\ Radiology and Radiological Science, Johns Hopkins University, Baltimore, Maryland; ${ }^{8}$ Department of Neurology, McGill University, \\ Montreal, Quebec, Canada; and ${ }^{9}$ Department of Nuclear Medicine, Odense University Hospital, Odense, Denmark
}

Degeneration of noradrenergic neurons may underlie the disabling nonmotor symptoms in patients with Parkinson disease (PD). Quantification of the loss of noradrenergic neurons by means of neuroimaging has been limited by the lack of radioligands that are selective for noradrenergic neurotransmission. The radioligand $(S, S)-{ }^{11} \mathrm{C}-2-(\alpha-(2-$ methoxyphenoxy)benzyl)morpholine ( $\left.{ }^{11} \mathrm{C}-\mathrm{MeNER}\right)$ is a highly selective inhibitor of noradrenaline transporters, and PET studies suggest that this radioligand is suitable for quantitative neuroimaging of noradrenergic deficits in human brain in vivo. In the present investigation, we used PET with ${ }^{11} \mathrm{C}-M e N E R$ to map the density of noradrenaline transporters in groups of patients with PD and age-matched healthy controls. Methods: After administration of ${ }^{11} \mathrm{C}-M e N E R, 15$ nondemented patients with PD and 10 healthy subjects underwent 90 -min dynamic PET. We determined ${ }^{11} \mathrm{C}-$ MeNER binding potential relative to nondisplaceable binding potential $\left(\mathrm{BP}_{\mathrm{ND}}\right)$ by multilinear analysis, simplified reference tissue model 2, and multilinear reference tissue model 2. Results: Metabolism of ${ }^{11} \mathrm{C}$ MeNER did not differ between groups. The simplified reference tissue model 2 and the multilinear reference tissue model 2 were used to determine ${ }^{11} \mathrm{C}-M e N E R \mathrm{BP}_{\mathrm{ND}} \cdot{ }^{11} \mathrm{C}-\mathrm{MeNER} \mathrm{BP}_{\mathrm{ND}}$ was reduced in the PD group compared with the control subjects, with regionally significant declines in the thalamus and nucleus ruber. Tremor was associated with higher tracer binding in the PD group on multivariate regression analysis. Conclusion: To our knowledge, this was the first specific quantification of noradrenergic denervation in PD patients in vivo. In agreement with predictions from determinations in vitro, we discovered a decline of noradrenergic projections in vivo in brain of PD patients.

Key Words: Parkinson disease; noradrenaline transporter; ${ }^{11} \mathrm{C}-$ MeNER; positron emission tomography

J Nucl Med 2018; 59:659-664

DOI: 10.2967/jnumed.117.190975

Received Feb. 13, 2017; revision accepted Jul. 18, 2017.

For correspondence or reprints contact: Adjmal Nahimi, Department of Nuclear Medicine and PET Centre, Aarhus University Hospitals, Noerrebrogade 44, Building 10G, 6th Floor, 8000 Aarhus C, Denmark.

E-mail: anah@clin.au.dk

Published online Aug. 28, 2017.

COPYRIGHT (C 2018 by the Society of Nuclear Medicine and Molecular Imaging.
$\mathbf{N}$ oradrenergic deficits are implicated in the occurrence of nonmotor symptoms in Parkinson disease (PD) patients. The nonmotor symptoms include cognitive impairment, sleep disorders, autonomic dysfunction, and mood disorders (1). The postmortem appearance of characteristic Lewy bodies in the locus coeruleus (LC) coincides with extensive loss of its noradrenaline-producing neurons and the subsequent depletion of noradrenergic innervation of cortical and subcortical structures in patients with PD (2). Similarly, lesioning of noradrenergic neurons leads to loss of noradrenergic neurons in the $\mathrm{LC}$, in parallel with loss of binding sites for noradrenaline transporters (3).

Here, we tested the claim that the density of noradrenaline transporters, as previously evaluated by postmortem autoradiography, may be a surrogate marker of the number of noradrenergic neurons in vivo (4). Previous attempts to quantify noradrenaline transporters in vivo were limited by the lack of suitable radioligands for quantitative PET. Recent clinical and preclinical studies suggest that the PET ligand $(S, S)-{ }^{11} \mathrm{C}-2-(\alpha-(2-m e t h o x y p h e n o x y)$ benzyl $)$ morpholine $\left({ }^{11} \mathrm{C}-\mathrm{MeNER}\right)$, a derivate of reboxetine and a highly selective inhibitor of noradrenaline transporters, is suitable for quantification of noradrenaline transporters in vivo (5). Here, we used ${ }^{11} \mathrm{C}$-MeNER PET to map noradrenergic deficits in vivo in patients with PD compared with age-matched healthy control subjects.

\section{MATERIALS AND METHODS}

\section{Subjects}

The Ethics Committee of the Central Denmark Region approved the study. All subjects provided written informed consent before participation. Fifteen PD patients ( 11 men) and 10 healthy age- and sex-matched control subjects (6 men) were recruited. The exclusion criterion was dementia, as assessed by a threshold of 24 on the Mini Mental State Examination and significant symptoms of depression as indicated by a score of more than 9 on the 30 -item geriatric depression scale, or established clinical depression and antidepressant treatment (6-8). All patients were recruited in collaboration with the Department of Neurology, Aarhus University Hospital, Denmark, and fulfilled the U.K. Parkinson Disease Society Brain Bank criteria for Parkinson disease (9). Motor function in patients was assessed using the Unified Parkinson Disease Rating Scale, part III (UPDRS-III), in the "off" state; patients with a score of 5 or more on item 20 were classified as tremor-positive. Levodopa-equivalent doses were 
calculated according to previously published conversions (10). Disease characteristics in patients are listed in Table 1 . None of the control subjects had any neurologic disorders.

\section{Radiochemistry}

The synthesis of ${ }^{11} \mathrm{C}-\mathrm{MeNER}$ was described in detail previously (11). Briefly, cyclotron-produced ${ }^{11} \mathrm{C}$-carbon dioxide was converted to ${ }^{11} \mathrm{C}$-methyliodide using the GE Healthcare Tracerlab FXcPro system. ${ }^{11} \mathrm{C}$-methyliodide was trapped in the reactor, which contained a solution of dimethylformamide ( $300 \mu \mathrm{L}$; Sigma-Aldrich), sodium hydroxide (10 $\mu \mathrm{L}, 3 \mathrm{~mol} / \mathrm{L})$, and precursor $(2 S, 3 S)-N$-Boc-norethylreboxetine $(0.8 \mathrm{mg}$; $\mathrm{ABX})$. After heating for $3 \mathrm{~min}$ at $90^{\circ} \mathrm{C}$, hydrochloric acid $(300 \mu \mathrm{L}$, $1 \mathrm{~mol} / \mathrm{L}$ ) was added to the reaction mixture to remove the Boc-protecting group $\left(4 \mathrm{~min}\right.$ at $\left.90^{\circ} \mathrm{C}\right)$. The reaction mixture was cooled and neutralized with sodium hydroxide $(600 \mu \mathrm{L}, 0.5 \mathrm{~mol} / \mathrm{L})$ before purification by semipreparative high-performance liquid chromatography. The mobile phase, consisting of $35 \%$ ethanol in $\mathrm{NaH}_{2} \mathrm{PO}_{4}$ buffer $(70 \mathrm{mmol} / \mathrm{L})$, was delivered at a rate of $15 \mathrm{~mL} / \mathrm{min}$ to a Phenomenex Synergi Fusion-RP $4 \mu$ $(150 \times 21.2 \mathrm{~mm})$ column with online radio- and ultraviolet-detection $(220 \mathrm{~nm})$. The fraction containing $(S, S)-{ }^{11} \mathrm{C}-\mathrm{MeNER}$ (retention time, $9 \mathrm{~min})$ was collected, diluted with water $(50 \mathrm{~mL})$, and subsequently concentrated on a solid-phase extraction cartridge (Sep-Pak Plus, C18; Waters). The final product was eluted with $1 \mathrm{~mL}$ of ethanol and formulated with $9 \mathrm{~mL}$ of isotonic saline and then underwent sterile filtration $(0.22 \mu \mathrm{m}$; Millex) into a sterile product vial. This procedure gave $1-2$ GBq of $(S, S)-{ }^{11} \mathrm{C}-\mathrm{MeNER}$ with radiochemical purity of more than $99 \%$ in a sterile formulation ready for injection. With regard to metabolites of $(S, S)-{ }^{11} \mathrm{C}-\mathrm{MeNER}$, the fraction of untransformed $(S, S)-{ }^{11} \mathrm{C}-\mathrm{MeNER}$ was

\section{TABLE 1}

Demographic, Radiotracer, and Clinical Characteristics of PD Patients and Healthy Subjects

\begin{tabular}{|c|c|c|c|}
\hline Parameter & $\begin{array}{l}\text { PD patients } \\
(n=15)\end{array}$ & $\begin{array}{l}\text { Controls } \\
(n=10)\end{array}$ & $P$ \\
\hline \multicolumn{4}{|l|}{ Demographics } \\
\hline Age (y) & $64.8 \pm 8.8$ & $65.7 \pm 8.2$ & 0.796 \\
\hline Sex (\% men) & 73.3 & 60 & 0.667 \\
\hline $\begin{array}{l}\text { Geriatric } \\
\quad \text { depression scale }\end{array}$ & $4.1 \pm 2.4$ & $2.1 \pm 2.8$ & 0.083 \\
\hline $\begin{array}{l}\text { Mini Mental State } \\
\text { Examination score }\end{array}$ & $28.4 \pm 1.5$ & $29.1 \pm 1.3$ & 0.250 \\
\hline \multicolumn{4}{|l|}{ Radiotracer } \\
\hline Injected dose (MBq) & $530.3 \pm 89.1$ & $523.6 \pm 104.5$ & 0.871 \\
\hline $\begin{array}{l}\text { Specific activity } \\
(\mathrm{MBq} / \mu \mathrm{mol})\end{array}$ & $66.7 \pm 56.1$ & $37.7 \pm 17.4$ & 0.238 \\
\hline \multicolumn{4}{|l|}{ Clinical characteristics } \\
\hline Disease duration & $9.9 \pm 2.8$ & & \\
\hline $\begin{array}{l}\text { Hoehn and Yahr } \\
\text { stage }\end{array}$ & $2.4 \pm 0.5$ & & \\
\hline UPDRS-III, "off" state & $42.3 \pm 7.5$ & & \\
\hline $\begin{array}{l}\text { Patients with } \\
\text { tremor }^{\star}(\%)\end{array}$ & 33 & & \\
\hline $\begin{array}{l}\text { Levodopa-equivalent } \\
\text { dose (mg) }\end{array}$ & $961.5 \pm 323.3$ & & \\
\hline
\end{tabular}

${ }^{*}$ Patients were classified as tremor-positive if they scored $\geq 5$ on sum of UPDRS-III item 20.

Data are mean $\pm S D$, except for age and patients with tremor.

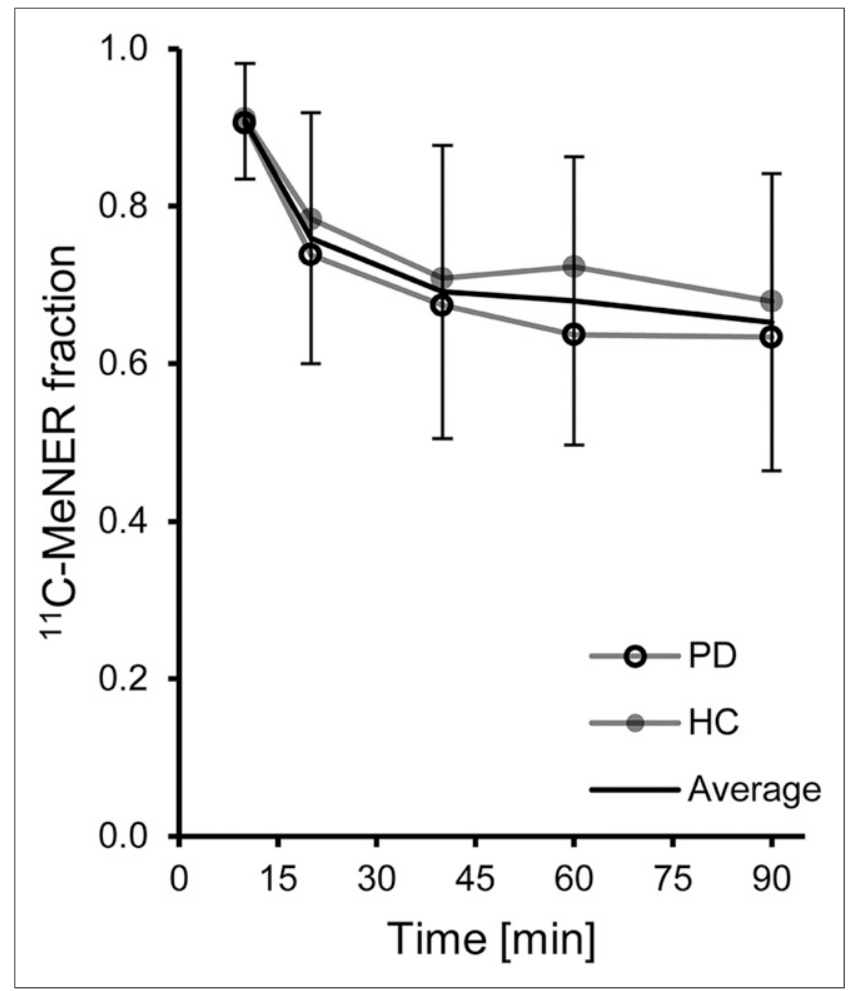

FIGURE 1. Metabolism of ${ }^{11} \mathrm{C}-M e N E R$ in $\mathrm{PD}$ patients and healthy controls $(H C)$, as well as averaged values \pm SD.

measured by high-performance liquid chromatography in extracts of plasma from arterial samples.

The specific activities of injected ${ }^{11} \mathrm{C}$-MeNER ranged between 3 and $211 \mathrm{MBq} / \mu \mathrm{mol}$ and did not significantly differ between PD patients and healthy controls $(66.7 \pm 56.1$ vs. $37.7 \pm 17.4 \mathrm{MBq} / \mu \mathrm{mol}$, $P=0.238)$. Specific activity did not correlate with total distribution volume $\left(V_{\mathrm{T}}\right)$ or nondisplaceable binding potential $\left(\mathrm{BP}_{\mathrm{ND}}\right)$ estimates (assessed in each brain region and each group separately, as well as in the global sample; all $P$ values $>0.05$ ) and was therefore not included as a covariate in the mixed linear model calculation.

\section{Image Acquisition}

The ${ }^{11} \mathrm{C}$-MeNER PET protocol was similar to that previously described using the ECAT high-resolution tomograph (CTI/Siemens) $(5,12)$. PD patients paused their dopaminergic medication overnight. A transmission scan was obtained, and 90-min dynamic PET sessions consisting of 27 frames of increasing duration were recorded in list mode on administration of a bolus of ${ }^{11} \mathrm{C}$-MeNER. Reconstruction was performed as previously described in detail (12). All subjects underwent T1-weighted anatomic MRI on another day.

\section{PET Image Processing and Delineation of Volumes of Interest (VOIs)}

We analyzed the PET images with the relevant toolboxes of PMOD (version 3.7). The motion correction realigned each frame to an average image of the first 10 frames, with manual adjustment of imprecise alignments. We used the maximum-probability atlas tool for normalization of PET images to the Montreal Neurological Institute space and assignment of VOIs, using the built-in Hammers N30R83 1-mm atlas. The assignment included rigid matching of the PET image to a subject's personal MR image, segmentation of the MR image, and alignment of atlas VOIs according to brain segmentation. The regions defined in the atlas were merged into 3 larger VOIs: caudate, thalamus, and occipital cortex. Additionally, VOIs 
for the LC and the median raphe were drawn according to previously published locations $(13,14)$. VOIs for the hypothalamus and the nucleus ruber were drawn according to their surrounding anatomic structures.

\section{Image Analysis}

We smoothed the images with a 4-mm gaussian filter and extracted time-activity curves from the VOIs for calculation of the $V_{\mathrm{T}}$ using multilinear analysis (MA1) (15). Blood and plasma data were linearly interpolated, and metabolite correction was fitted with a Watabe function (16). ${ }^{11} \mathrm{C}-\mathrm{MeNER} \mathrm{BP}_{\mathrm{ND}}$ values were estimated from $V_{\mathrm{T}}$ values calculated with MA1 and estimates derived by the simplified reference tissue model 2 (SRTM2) and multilinear reference tissue model 2 (MRTM2) methods $(17,18)$. The caudate and occipital cortex were evaluated as reference regions for $\mathrm{BP}_{\mathrm{ND}}$ calculation because both regions have low levels of noradrenaline transporters (19). The efflux rate constants of the reference regions, $k_{2}{ }^{\prime}$, were calculated with a 1-tissue-compartment model, with metabolite-corrected arterial blood curves as input functions. Because $k_{2}{ }^{\prime}$ estimates did not differ between patients and control subjects (caudate, $0.0330 \pm 0.0112 \mathrm{~min}^{-1}$ in PD vs. $0.0317 \pm$ $0.0105 \mathrm{~min}^{-1}$ in controls, $P=0.794$; occipital cortex, $0.0393 \pm 0.0122 \mathrm{~min}^{-1}$ in PD vs. $0.0375 \pm 0.0118 \mathrm{~min}^{-1}$ in controls, $P=$ 0.737), a population average was used for reference tissue model calculations (caudate, $0.0325 \mathrm{~min}^{-1}$; and occipital cortex, 0.0386 $\mathrm{min}^{-1}$ ). In patients for whom the blood sampling failed $(n=2)$, only the SRTM2 and MRTM2 models were calculated. Parametric maps of SRTM2 $\mathrm{BP}_{\mathrm{ND}}$ were calculated from the smoothed and normalized PET images in the PXMOD toolbox.

\section{Statistics and Data Analysis}

We analyzed the data with the Statistical Package for the Social Sciences, version 21. Group data are presented as mean \pm SD or as relative frequencies if not otherwise stated. Univariate correlation analysis was calculated with Pearson $r$, and multivariate analysis was calculated with multiple linear regression analysis. Differences between groups in demographic and radiotracer characteristics were evaluated with the Student $t$ test or Mann-Whitney $U$ test, as appropriate. For metabolite analysis between healthy controls and PD patients, we calculated a mixed model with group and time as fixed factors and time as a repeated measure in an antedependent covariance structure. For VOI-based PET analysis, a mixed model was calculated with group and region as fixed factors, age as a covariate, and subject identification number plus intercept as random factors; subject identification number and region were set as repeated measures with a compound symmetry covariance structure. Regionwise post hoc analyses were corrected with Bonferroni adjustment.

\section{RESULTS}

\section{Metabolites of ${ }^{11} \mathrm{C}$-MeNER in Healthy Controls and Patients}

Metabolism of ${ }^{11} \mathrm{C}$-MeNER did not differ between PD patients and healthy controls $(P=0.831$ for group effect). On average, the fraction of unmetabolized ${ }^{11} \mathrm{C}-\mathrm{MeNER}$ was $90.8 \% \pm 7.3 \%$ after $10 \mathrm{~min}, 75.9 \% \pm 15.9 \%$ after $20 \mathrm{~min}$, and $65.2 \% \pm 18.9 \%$ after $90 \mathrm{~min}$ in arterial

plasma (Fig. 1).
FIGURE 2. (A) PD patients and healthy subjects showed comparable $V_{\mathrm{T}}$ values in caudate and occipital cortex obtained with MA1 model, but $V_{\mathrm{T}}$ values in occipital cortex were slightly higher than in caudate. (B) Correspondingly, estimates of $\mathrm{BP}_{\mathrm{ND}}$ values were lower with occipital cortex $(\mathrm{OC})$ as reference compared with caudate as reference. ( $C$ and $D) \mathrm{BP}_{\mathrm{ND}}$ estimates were comparable between models requiring blood samples and reference tissue models. (E and $F$ ) Estimates of $\mathrm{BP}_{\mathrm{ND}}$ were comparable between SRTM2 and MRTM2 calculation. Dotted lines = line of identity; black line = mean difference; gray lines $= \pm 1.96 \mathrm{SD} ; \mathrm{HC}=$ healthy controls. 


\section{Reference Region for ${ }^{11} \mathrm{C}-M e N E R$ in PD}

In agreement with the known distribution of noradrenaline transporters, the caudate exhibited the lowest $V_{\mathrm{T}}$ estimate of all examined brain regions, and it did not differ between PD patients and healthy controls $(2.641 \pm 0.959$ vs. $2.739 \pm 1.089,3.6 \%$ relative difference, $P=0.831$; Fig. $2 \mathrm{~A}$ ). Mean $V_{\mathrm{T}}$ values also were lower in the caudate nucleus than in the occipital cortex $(2.679 \pm 1.012$ vs. $3.030 \pm 0.995, P<0.001$ ). Estimates of ${ }^{11} \mathrm{C}-\mathrm{MeNER} \mathrm{BP}_{\mathrm{ND}}$ derived from the occipital cortex as a reference correlated well with $\mathrm{BP}_{\mathrm{ND}}$ values with the caudate as a reference but were lower $(r=0.892, P<$ 0.001; Fig. 2B). Estimates of ${ }^{11} \mathrm{C}-\mathrm{MeNER} \mathrm{BP}_{\mathrm{ND}}$ derived from the MA1 model correlated with estimates derived from the SRTM2 model and with estimates from the MRTM2 model $(r=0.821, P<$ $0.001, R^{2}=0.8$, and $r=0.903, P<0.001, R^{2}=0.9$, respectively; Figs. $2 \mathrm{C}$ and $2 \mathrm{D}$ ) with caudate as a reference. The results for the 2 reference tissue models were highly comparable, with slightly higher estimates derived with the MRTM2 model $(r=0.907, P<0.001$, $R^{2}=0.9$; Figs. $2 \mathrm{E}$ and $2 \mathrm{~F}$ ). With occipital cortex as a reference, the ${ }^{11} \mathrm{C}-\mathrm{MeNER} \mathrm{BP}_{\mathrm{ND}}$ estimates were also comparable to the MA1 and reference tissue approaches, but they were lower than with the caudate nucleus as a reference (Supplemental Fig. 1; supplemental materials are available at http://jnm.snmjournals.org).

\section{Binding Potentials of ${ }^{11} \mathrm{C}-\mathrm{MeNER}$ in PD}

Patients with $\mathrm{PD}$ had lower values of $\mathrm{BP}_{\mathrm{ND}}$ for ${ }^{11} \mathrm{C}-\mathrm{MeNER}$ than healthy control subjects in all examined brain regions. The average reduction was $33.66 \% \pm 12.06 \%(P=0.008$ for group effect $)$ with SRTM2 and $28.33 \% \pm 9.97 \%(P=0.004$ for group effect) with MRTM2, as shown in Figure 3 and listed in Table 2. Age was not a significant covariate $(P=0.329$ and $P=0.529$, respectively). Parametric maps of ${ }^{11} \mathrm{C}-\mathrm{MeNER} \mathrm{BP}_{\mathrm{ND}}$ are shown in Figure 4. The $\mathrm{BP}_{\mathrm{ND}}$ values were even lower with occipital cortex as a reference region, and the differences between groups and regions were slightly less significant $(P=0.015$ [SRTM2] and $P=0.006$ [MRTM2] for group effect; Supplemental Fig. 2).

To test potential PD-related factors in ${ }^{11} \mathrm{C}$-MeNER binding, we included age, disease duration, Hoehn and Yahr stage, levodopaequivalent doses, total UPDRS-III scores, and tremor occurrence in a multivariate linear regression analysis with thalamic $\mathrm{BP}_{\mathrm{ND}}$ as a dependent factor. Tremor was associated with higher ${ }^{11} \mathrm{C}$ MeNER binding and was the only significant PD-related measure ( $\beta=0.625, P=0.023, R^{2}=0.8$, for SRTM2 and $\beta=0.649, P=$ $0.027, R^{2}=0.7$, for MRTM2)

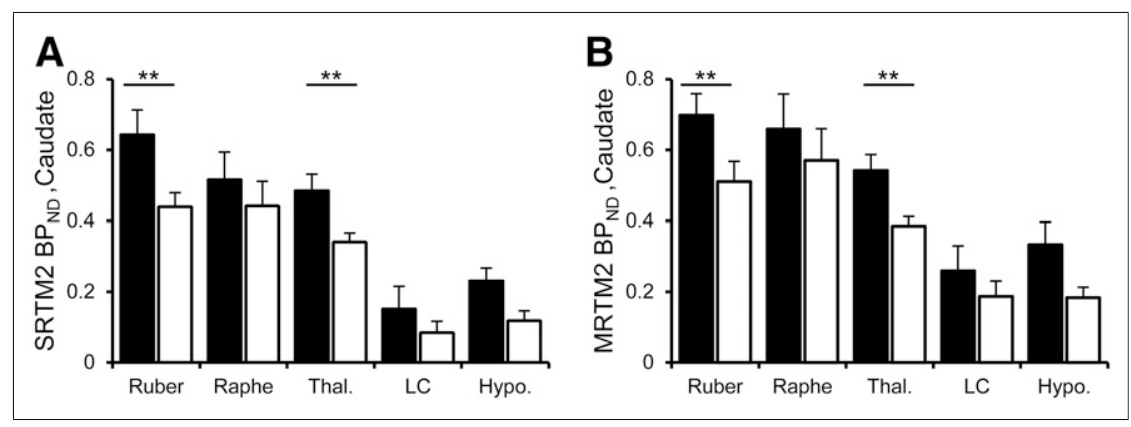

FIGURE 3. PD patients showed decreased ${ }^{11} \mathrm{C}-\mathrm{MeNER} \mathrm{BP}_{\mathrm{ND}}$, with caudate as reference, compared with healthy controls in various regions with high levels of noradrenaline transporters (group effect: $P=0.008$ for SRTM2 analysis $[\mathrm{A}]$ and $P=0.004$ for MRTM2 analysis [B]). ${ }^{*} P<0.05$ and ${ }^{\star \star} P<0.01$ (regionwise significant differences after Bonferroni adjustment). Ruber $=$ nucleus ruber, Raphe $=$ median raphe nucleus, Thal. = thalamus, Hypo. $=$ hypothalamus.
Here, we report findings from the first - to our knowledge${ }^{11} \mathrm{C}-\mathrm{MeNER}$ study of noradrenaline transporters in PD patients. The estimates of ${ }^{11} \mathrm{C}$-MeNER $\mathrm{BP}_{\mathrm{ND}}$ were lower in the brains of $\mathrm{PD}$ patients than in healthy control subjects in structures with known dense noradrenergic projections (Fig. 2; Table 2). The finding of lower $\mathrm{BP}_{\mathrm{ND}}$ values for ${ }^{11} \mathrm{C}-\mathrm{MeNER}$ agrees with previous findings in vitro and with observations of extensive LC involvement in PD pathology $(20,21)$. In previous in vivo imaging studies, authors quantified the degree of noradrenergic depletion in patients with PD with nonselective PET ligands. Pavese et al. reported that the monoamine synthesis capacity in the dorsal midbrain declined at an annual rate of $8 \%$ in PD patients (22). Remy et al. used the tracer ${ }^{11}$ C-RTI-32, an inhibitor of catecholamine transporters, to reveal reduced binding of ${ }^{11} \mathrm{C}$-RTI-32 in limbic structures in depressed PD patients compared with nondepressed patients (23). The inhibitor ${ }^{11} \mathrm{C}$-RTI-32 has affinities similar to the dopamine and noradrenaline transporters, and ${ }^{18} \mathrm{~F}-\mathrm{FDOPA}$ is subject to decarboxylation in all 3 monoaminergic neuron types $(23,24)$. The radioligand ${ }^{11} \mathrm{C}$ MeNER, on the other hand, is subject to highly selective binding to noradrenaline transporters, with negligible affinity to dopamine and serotonin transporters (25). Postmortem autoradiography showed that ${ }^{3} \mathrm{H}-\mathrm{MeNER}$ binding is diminished in mice that lack noradrenaline transporters (26), and PET studies with ${ }^{11} \mathrm{C}$-MeNER showed that the binding to noradrenaline transporters can be displaced with both methylphenidate and atomoxetine, which further supports the applicability in clinical studies $(5,25)$.

Thus, the current study is the first to specifically quantify deficient noradrenergic neurotransmission in vivo in $\mathrm{PD}$ patients. The finding of a decline of ${ }^{11} \mathrm{C}-\mathrm{MeNER} \mathrm{BP}_{\mathrm{ND}}$ in the examined brain regions of $\mathrm{PD}$ patients may result in altered noradrenergic neurotransmission in PD. Autoradiography with ${ }^{3} \mathrm{H}$-nisoxetine demonstrated an age-dependent decline of noradrenaline transporters (27), and Ding et al. reported the age-dependent decline of ${ }^{11} \mathrm{C}$-MeNER binding in 12 healthy controls, which may reflect a loss of noradrenergic neurons with aging (28). We controlled for the effect of age-dependent changes in 2 ways, first by matching the groups for age, and second by including age as a covariate in the analysis. We did not find a significant association between age and the ${ }^{11} \mathrm{C}-\mathrm{MeNER} \mathrm{BP}_{\mathrm{ND}}$ estimates in the present data, possibly because of a narrower age range and an older age on average of the subjects, as well as a slightly different choice of reference, compared with previous studies.

We found no associations between ${ }^{11} \mathrm{C}-\mathrm{MeNER} \mathrm{BP}_{\mathrm{ND}}$ estimates and disease severity in terms of disease duration, disease stage, or severity of motor symptoms. The lack of association between clinical indicators and ${ }^{11} \mathrm{C}-\mathrm{MeNER}$ $\mathrm{BP}_{\mathrm{ND}}$ in part may reflect the pattern of disease progression in $\mathrm{PD}$, in which $\mathrm{LC}$ neurons are likely to be affected in the early stages, even before the appearance of classic motor symptoms. Accordingly, German et al. found a correlation with disease duration and LC cell loss in Alzheimer disease but not in PD patients (29). However, tremor symptoms in PD patients were associated with a higher ${ }^{11} \mathrm{C}-\mathrm{MeNER} \mathrm{BP}_{\mathrm{ND}}$ in the thalamus than in patients without tremor. This finding may point to an influence of thalamic 
TABLE 2

Regional ${ }^{11} \mathrm{C}-\mathrm{MeNER} \mathrm{BP}_{\mathrm{ND}}$ in PD Patients and Healthy Subjects

\begin{tabular}{|c|c|c|c|c|c|c|c|}
\hline \multirow[b]{2}{*}{ Brain region } & \multirow[b]{2}{*}{ Group } & \multicolumn{3}{|c|}{ SRTM2 } & \multicolumn{3}{|c|}{ MRTM2 } \\
\hline & & $\mathrm{BP}_{\mathrm{ND}}$ & Relative reduction & $P^{*}$ & $\mathrm{BP}_{\mathrm{ND}}$ & Relative reduction & $P^{\star}$ \\
\hline \multirow[t]{2}{*}{ Nucleus ruber } & $\mathrm{HC}$ & $0.64 \pm 0.22$ & 31.71 & 0.002 & $0.70 \pm 0.19$ & 26.92 & 0.015 \\
\hline & PD & $0.44 \pm 0.15$ & & & $0.51 \pm 0.22$ & & \\
\hline \multirow[t]{2}{*}{ Median raphe } & $\mathrm{HC}$ & $0.52 \pm 0.25$ & 14.34 & 0.458 & $0.66 \pm 0.31$ & 13.37 & 0.498 \\
\hline & PD & $0.44 \pm 0.27$ & & & $0.57 \pm 0.34$ & & \\
\hline \multirow[t]{2}{*}{ Thalamus } & $\mathrm{HC}$ & $0.48 \pm 0.15$ & 29.50 & 0.008 & $0.54 \pm 0.14$ & 28.85 & 0.004 \\
\hline & PD & $0.34 \pm 0.10$ & & & $0.39 \pm 0.10$ & & \\
\hline \multirow[t]{2}{*}{ LC } & $\mathrm{HC}$ & $0.15 \pm 0.20$ & 44.26 & 0.295 & $0.26 \pm 0.22$ & 27.72 & 0.355 \\
\hline & PD & $0.08 \pm 0.12$ & & & $0.19 \pm 0.17$ & & \\
\hline \multirow[t]{2}{*}{ Hypothalamus } & $\mathrm{HC}$ & $0.23 \pm 0.12$ & 48.49 & 0.104 & $0.33 \pm 0.20$ & 44.78 & 0.056 \\
\hline & PD & $0.12 \pm 0.11$ & & & $0.18 \pm 0.20$ & & \\
\hline
\end{tabular}

${ }^{\star} P$ values were corrected for multiple comparisons with Bonferroni adjustment: overall group effect at $P=0.040$ for SRTM2 estimates and $P=0.043$ for MRTM2 estimates.

$\mathrm{HC}=$ healthy control.

Data are regional mean $\mathrm{BP}_{\mathrm{ND}} \pm \mathrm{SD}$.

noradrenergic innervation in tremor genesis, with the thalamus held to be a generator in the PD tremor network (30,31). Moreover, PARK2 carriers, who develop a genetic variant of PD commonly accompanied by tremor symptoms, have more preserved noradrenergic neurons in the LC compared with dopaminergic neurons in the substantia nigra pars compacta (32). When compared with the akinetic-rigid subtype, PD patients with tremordominant disease exhibit a more benign course of disease with slower

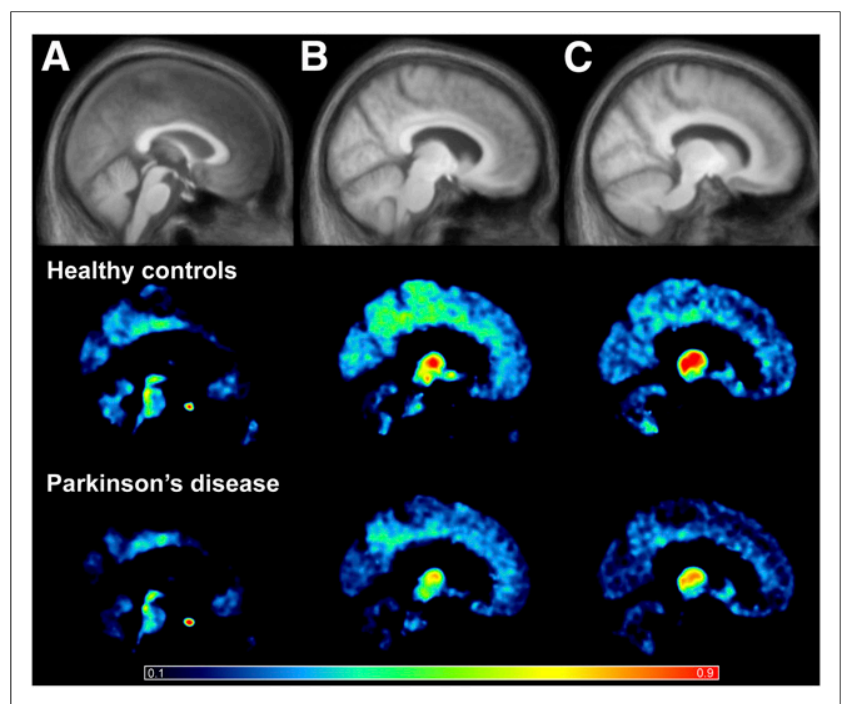

FIGURE 4. Average of ${ }^{11} \mathrm{C}-\mathrm{MeNER} \mathrm{BP}_{\mathrm{ND}}$ with SRTM2 parametric maps using caudate as reference region. ${ }^{11} \mathrm{C}-\mathrm{MeNER} \mathrm{BP}_{\mathrm{ND}}$ maps are scaled from 0.1 (blue) to 0.9 (red). Top row shows average of MRI scans of all 25 subjects; middle row, $\mathrm{BP}_{\mathrm{ND}}$ parametric maps of healthy controls; and bottom row, $\mathrm{BP}_{\mathrm{ND}}$ parametric maps of PD patients. Sections are given in median plane for raphe nuclei (A); paramedian plane for nucleus ruber, hypothalamus, and part of thalamus (B); and further lateral in mid plane for thalamus (C). Tracer binding is completely lacking in caudate and low in occipital cortex. progression of motor and nonmotor symptoms, lower frequency of cognitive impairment, and better preserved noradrenergic neurons $(31,33,34)$, not unlike the relatively mild disease progression in PARK2 carriers. However, because only a minor subset of patients $(n=5)$ had significant tremor symptoms, the current relation between ${ }^{11} \mathrm{C}-\mathrm{MeNER} \mathrm{BP}_{\mathrm{ND}}$ and tremor should be considered preliminary; further work with larger patient groups is needed.

Because noradrenergic deterioration encompasses the entire brain in PD, some technical issues of the present study are notable. We chose the caudate nucleus and occipital cortex as reference regions because they have low expression of noradrenaline transporters $(26,27)$ and have shown negligible displacement of ${ }^{11} \mathrm{C}$-MeNER in drug challenge studies $(35,36)$. In ${ }^{3} \mathrm{H}$-nisoxetine autoradiography, the caudate nucleus is devoid of binding, and low binding is evident in all cortical regions, in agreement with our findings of higher $V_{\mathrm{T}}$ values in the occipital cortex than in the caudate nucleus and some binding of ${ }^{11} \mathrm{C}$-MeNER visible in the parametric maps of the occipital region. The caudate nucleus also exhibited the lowest $V_{\mathrm{T}}$ value of all examined regions, with a negligible difference between the groups (3.6\% relative difference). The resulting estimates of $\mathrm{BP}_{\mathrm{ND}}$ were in the range of previously reported values obtained with the occipital cortex as a reference region, although subjects tended to be younger in previous studies, perhaps reflecting less influence of age-dependent factors in our analysis $(5,28)$. The specific activities of ${ }^{11} \mathrm{C}-\mathrm{MeNER}$ ranged between 3 and $211 \mathrm{MBq} / \mu \mathrm{mol}$; however, we could not find any influence on the $V_{\mathrm{T}}$ or $\mathrm{BP}_{\mathrm{ND}}$ estimates. This points to only a minor influence of the specific activity of ${ }^{11} \mathrm{C}-\mathrm{MeNER}$ on binding estimates, as the total injected dose of ${ }^{11} \mathrm{C}$-MeNER was kept below pharmacologic doses. We could not find significant differences between the use of the SRTM2 and the MRTM2 for group comparison. Therefore, we conclude that both models may be valid for estimating ${ }^{11} \mathrm{C}-\mathrm{MeNER} \mathrm{BP}_{\mathrm{ND}}$ in our subjects.

On average, the decrease of displaceable ${ }^{11} \mathrm{C}$-MeNER binding was nearly one third. This finding agrees with previous postmortem autoradiography studies on patients with Alzheimer disease-studies that found binding of ${ }^{3} \mathrm{H}$-nisoxetine to be reduced by $40 \%-50 \%$. 
However, loss of biochemically detectable noradrenaline was considerably higher in previous postmortem studies $(20,37)$. The differences in methodologies and different compensatory mechanisms for neurotransmitter levels versus noradrenaline transporters may explain the disparity in the quantification of the extent of noradrenergic degeneration between the different methods.

\section{CONCLUSION}

In agreement with previous in vitro studies, we now provide in vivo evidence that noradrenergic projections undergo degeneration in PD as quantified by means of ${ }^{11} \mathrm{C}-\mathrm{MeNER}$ PET. Longitudinal studies that relate loss of noradrenaline, as measured with ${ }^{11} \mathrm{C}-\mathrm{MeNER}$ PET, to the occurrence of nonmotor symptoms in PD patients are warranted.

\section{DISCLOSURE}

This project received financial support from the Lundbeck Foundation (grant 6970), the Danish Council for Independent Research, Medical Sciences (grant 0602-02700), the Aarhus University Research Foundation, the Danish Association of Parkinson's disease (Parkinson-foreningen), the Swiss National Science Foundation (grant P2SKP3_161812), and the Hildegard Henssler-Stiftung. No other potential conflict of interest relevant to this article was reported.

\section{REFERENCES}

1. Chaudhuri KR, Schapira AHV. Non-motor symptoms of Parkinson's disease: dopaminergic pathophysiology and treatment. Lancet Neurol. 2009;8:464-474.

2. Braak H, Del Tredici K, Rüb U, de Vos RAI, Jansen Steur ENH, Braak E. Staging of brain pathology related to sporadic Parkinson's disease. Neurobiol Aging. 2003;24:197-211.

3. Tejani-Butt SM. $\left[{ }^{3} \mathrm{H}\right]$ nisoxetine: a radioligand for quantitation of norepinephrine uptake sites by autoradiography or by homogenate binding. J Pharmacol Exp Ther. 1992;260:427-436.

4. Ordway GA, Stockmeier CA, Cason GW, Klimek V. Pharmacology and distribution of norepinephrine transporters in the human locus coeruleus and raphe nuclei. J Neurosci. 1997; 17:1710-1719.

5. Hannestad J, Gallezot J-D, Planeta-Wilson B, et al. Clinically relevant doses of methylphenidate significantly occupy norepinephrine transporters in humans in vivo. Biol Psychiatry. 2010;68:854-860.

6. Folstein MF, Folstein SE, McHugh PR. "Mini-mental state": a practical method for grading the cognitive state of patients for the clinician. J Psychiatr Res. 1975;12:189-198.

7. Yesavage JA, Brink TL, Rose TL, et al. Development and validation of a geriatric depression screening scale: a preliminary report. J Psychiat Res Research. 1982; 17:37-49.

8. Mogensen F. GDS: geriatrisk depressionsskala. Manedsskr Prakt Laegegern. 1995;73:633-636.

9. Hughes AJ, Daniel SE, Kilford L, Lees AJ. Accuracy of clinical diagnosis of idiopathic Parkinson's disease: a clinico-pathological study of 100 cases. J Neurol Neurosurg Psychiatry. 1992;55:181-184.

10. Tomlinson CL, Stowe R, Patel S, Rick C, Gray R, Clarke CE. Systematic review of levodopa dose equivalency reporting in Parkinson's disease. Mov Disord. 2010;25:2649-2653.

11. Wilson AA, Patrick Johnson D, Mozley D, et al. Synthesis and in vivo evaluation of novel radiotracers for the in vivo imaging of the norepinephrine transporter. Nucl Med Biol. 2003;30:85-92.

12. Nahimi A, Jakobsen S, Munk OL, et al. Mapping $\alpha_{2}$ adrenoceptors of the human brain with ${ }^{11} \mathrm{C}$-yohimbine. J Nucl Med. 2015;56:392-398.
13. Keren NI, Lozar CT, Harris KC, Morgan PS, Eckert MA. In-vivo mapping of the human locus coeruleus. Neuroimage. 2009;47:1261-1267.

14. Kranz GS, Hahn A, Savli M, Lanzenberger R. Challenges in the differentiation of midbrain raphe nuclei in neuroimaging research. Proc Natl Acad Sci USA. 2012;109:E2000.

15. Ichise M, Toyama H, Innis RB, Carson RE. Strategies to improve neuroreceptor parameter estimation by linear regression analysis. J Cereb Blood Flow Metab. 2002;22:1271-1281.

16. Watabe H, Channing MA, Der MG, et al. Kinetic analysis of the 5-HT2A ligand $\left[{ }^{11}\right.$ C]MDL 100,907. J Cereb Blood Flow Metab. 2000;20:899-909.

17. Ichise M, Liow J-S, Lu J-Q, et al. Linearized reference tissue parametric imaging methods: application to $\left[{ }^{11} \mathrm{C}\right] \mathrm{DASB}$ positron emission tomography studies of the serotonin transporter in human brain. J Cereb Blood Flow Metab. 2003;23:10961112.

18. Wu Y, Carson RE. Noise reduction in the simplified reference tissue model for neuroreceptor functional imaging. J Cereb Blood Flow Metab. 2002;22:1440-1452.

19. Smith HR, Beveridge TJR, Porrino LJ. Distribution of norepinephrine transporters in the non-human primate brain. Neuroscience. 2006;138:703-714.

20. Pifl C, Kish SJ, Hornykiewicz O. Thalamic noradrenaline in Parkinson's disease: deficits suggest role in motor and non-motor symptoms. Mov Disord. 2012;27: $1618-1624$.

21. Zarow C, Lyness SA, Mortimer JA, Chui HC. Neuronal loss is greater in the locus coeruleus than nucleus basalis and substantia nigra in Alzheimer and Parkinson diseases. Arch Neurol. 2003;60:337-341.

22. Pavese N, Rivero-Bosch M, Lewis SJ, Whone AL, Brooks DJ. Progression of monoaminergic dysfunction in Parkinson's disease: a longitudinal ${ }^{18} \mathrm{~F}$-dopa PET study. Neuroimage. 2011;56:1463-1468

23. Remy P, Doder M, Lees A, Turjanski N, Brooks D. Depression in Parkinson's disease: loss of dopamine and noradrenaline innervation in the limbic system. Brain. 2005;128:1314-1322.

24. Carroll FI, Scheffel U, Dannals RF, Boja JW, Kuhar MJ. Development of imaging agents for the dopamine transporter. Med Res Rev. 1995;15:419-444.

25. Schou M, Halldin C, Sóvágó J, et al. Specific in vivo binding to the norepinephrine transporter demonstrated with the PET radioligand, $(S, S)-\left[{ }^{11} \mathrm{C}\right] \mathrm{MeNER}$. Nucl Med Biol. 2003;30:707-714.

26. Ghose S, Fujita M, Morrison $\mathrm{P}$, et al. Specific in vitro binding of $(S, S)$ $\left[{ }^{3} \mathrm{H}\right] \mathrm{MeNER}$ to norepinephrine transporters. Synapse. 2005;56:100-104.

27. Tejani-Butt SM, Ordway GA. Effect of age on $\left[{ }^{3} \mathrm{H}\right]$ nisoxetine binding to uptake sites for norepinephrine in the locus coeruleus of humans. Brain Res. 1992;583: 312-315.

28. Ding Y-S, Singhal T, Planeta-Wilson B, et al. PET imaging of the effects of age and cocaine on the norepinephrine transporter in the human brain using $(S, S)$ $\left[{ }^{11} \mathrm{C}\right] \mathrm{O}-\mathrm{methylreboxetine} \mathrm{and} \mathrm{HRRT.} \mathrm{Synapse.} \mathrm{2010;64:30-38.}$

29. German DC, Manaye KF, White CL, et al. Disease-specific patterns of locus coeruleus cell loss. Ann Neurol. 1992;32:667-676.

30. Duval C, Daneault J-F, Hutchison WD, Sadikot AF. A brain network model explaining tremor in Parkinson's disease. Neurobiol Dis. 2016;85:49-59.

31. Fereshtehnejad S-M, Romenets SR, Anang JBM, Latreille V, Gagnon J-F, Postuma RB. New clinical subtypes of Parkinson disease and their longitudinal progression: a prospective cohort comparison with other phenotypes. JAMA Neurol. 2015;72:863-873.

32. Doherty KM, Silveira-Moriyama L, Parkkinen L, et al. Parkin disease: a clinicopathologic entity? JAMA Neurol. 2013;70:571-579.

33. Baumann CR, Held U, Valko PO, Wienecke M, Waldvogel D. Body side and predominant motor features at the onset of Parkinson's disease are linked to motor and nonmotor progression. Mov Disord. 2014;29:207-213.

34. Paulus W, Jellinger K. The neuropathologic basis of different clinical subgroups of Parkinson's disease. J Neuropathol Exp Neurol. 1991;50:743-755.

35. Gallezot J-D, Weinzimmer D, Nabulsi N, et al. Evaluation of $\left[{ }^{11} \mathrm{C}\right] \mathrm{MRB}$ for assessment of occupancy of norepinephrine transporters: studies with atomoxetine in non-human primates. Neuroimage. 2011;56:268-279.

36. Logan J, Ding Y-S, Lin K-S, Pareto D, Fowler J, Biegon A. Modeling and analysis of PET studies with norepinephrine transporter ligands: the search for a reference region. Nucl Med Biol. 2005;32:531-542.

37. Kish SJ, Shannak KS, Rajput AH, Gilbert JJ, Hornykiewicz O. Cerebellar norepinephrine in patients with Parkinson's disease and control subjects. Arch Neurol. 1984;41:612-614. 